\title{
Non-specific factors that influence susceptibility to leprosy
}

\author{
RJW REES \\ Laboratory for Leprosy \& Mycobacterial Research, National Institute for \\ Medical Research, Mill Hill, London, NW7 IAA, England.
}

My brief for this section was to present and discuss aspects of non-specific factors including nutritional, environmental and other socia-economic factors that may influence susceptibility to leprosy and whether any of these factors can be used to define high risk groups. I have chosen to define "non-specific immunity" in its broadest sense i.e. the immune status of the non-leprosy individual or leprosy patient not specifically determined by exposure to Mycobacterium leprae. By this definition and critical analysis of past claims, a part of my presentation will also where necessary challenge or refute the evidence for such nonspecific associations.

\section{Nutritional Factors}

It is well-known that $M$. leprae does not infect all humans exposed to it, nor does it produce the same degree of illness in those who do become infected. Although a variety of risk factors have been invoked to explain this variation, it is not surprising that the state of nutrition of the individual at risk had been considered a possible and important factor, bearing in mind that currently leprosy predominates in parts of the world where malnutrition is rife. Thus a positive association between malnutrition and increased susceptibility and severity to leprosy has been frequently referred to in the leprosy literature and in particular and most forcibly by Ryrie (1) and Skinsnes (2,3). On the other hand Davey (4) and Leiker (5) conclude that the nutritional status did not seem to have significant influence on the susceptibility to leprosy, nor on the course of disease. Before considering the limited literature on leprosy and malnutrition, I will briefly review the pertinent information on malnutrition, and immunity.

The effect of nutritional status on the immune capacity and immune responses 
In the developing world, malnutrition and infection count for the majority of deaths, particularly among children. The two interreact synergistically in that infectious illness brings about a deterioration in the nutritional status and malnutrition worsens infection. The most important mechanisms responsible for this interaction are a decrease in immune capacity associated with malnutrition and catabolism caused by febrile illnesses. The human nutritional studies have focused principally on severe proteincalorie malnutrition (PCM), resulting in kwashiorkor or marasmus as well as the more prevalent but milder forms of PCM, resulting in growth retardation. This retardation has been measured on a weight-for-age basis and standardised as a percentile of the Harvard medium. There is now a vast amount of data on individuals with varying degrees of PCM. The immunological parameters measured have included cell-mediated immune (CMI) and hum ral immune, responses. CMI has been most commonly measured by post-BCG tuberculin sensitivity, which as a mycobacterium is of particular relevance to leprosy. Humoral immune responses have frequently been measured by means of tetanus or diptheria antibody production following the respective vaccines. Immunoglobulins $A, G$ and $M$ and complement $\mathrm{C}_{3}$ have also been studied. All these studies have shown that kwashiorkor, marasmus and more severe PCM ( $80 \%$ or less on the Harvard scale) cripple CMI responses more than the immunoglobulin-forming system. Usually normal or even elevated serum immunoglobulin concentrations have been found as well as good tetanus or diptheria antibody production in PCM. Raised IgG level can frequently be found and, of interest to leprosy, some studies have shown reduced $\operatorname{IgA}$ and $\mathrm{C}_{3}$ levels in the more severe PCM. An example of reduced CMI responses in children with various levels of PCM on the Harvard scale are shown in Table 1 from a study carried out in West Bengal measuring the post $B C G$ responses to P.P.D. (6).

Table 1. Comparison of Post-BCG (6-8 weeks) response to P.P.D. and Nutritional Status of Children

\begin{tabular}{cccc} 
P.P.D. & $\begin{array}{c}(5 \mathrm{~T} . \mathrm{U} .) \\
(\mathrm{mm})\end{array}$ & response & \multicolumn{2}{c}{$\begin{array}{c}\text { Nof children per Harvard } \\
\text { nutritional status }(\%)\end{array}$} \\
\cline { 2 - 4 } & $>80$ & $60-80$ & $<6$ \\
\hline-4 & 10 & 69 & 26 \\
$>5$ & $14(58.3)$ & $69(50.0)$ & $9(25.7)$ \\
\hline
\end{tabular}

Figures in parenthesis $\%$ of children with positive P.P.D. response. 
In a similar study on PCM children in Uganda it was shown that those who failed to convert to P.P.D. following BCG vaccination responded positively (10 $\mathrm{mm}$ induration) to a further P.P.D. test, two weeks after the children were given a diet containing $4 \mathrm{~g}$ protein/Kg body weight (7). The diminished CMI responses in these BCG studies showed as a failure to become sensitised rather than as a diminished response to P.P.D., so that there was no significant difference between the sizes of the reactions and the severity of PCM in the children.

Malnutrition as a risk factor in leprosy

Since CMI, which also requires intact macrophage function, is the major defence mechanism of the body against leprosy and other mycobacterial infections, PCM, particularly chronic PCM, which is known to suppress CMI, could well be a risk factor in leprosy. Furthermore, CMI is operative in the reversal-type reactions associated with BT and borderline leprosy as is activation of complement operative in ENL-type reactions in lepromatous leprosy. Therefore associated $\mathrm{PCM}$, which is known to result in low levels of $\mathrm{C}_{3}$, would also alter the course of the disease. Unfortunately the available and relevant data on malnutrition in leprosy and experimental animal infections is meagre.

\section{Studies in animals}

The most appropriate experiments concerned with PCM were undertaken in mice (8) and in rats (3) with Mycobacterium lepraemurium infections. Taken together the study showed that the profoundly protein-calorie deficient animals, compared with the well-fed animals, had a more severe and diseminated infection. Moreover, the macrophages in the PCM animals formed fewer granuloma, contained more bacilli and were enzymatically deficient compared with the well-fed animals. The results of the M. lepraemurium experiments are consistent with other Mycobacterium tuberculosis studies showing deficient anti-bacterial defences in severe PCM.

\section{Studies in man}

One of the main claims for association between malnutrition and severity of leprosy was based on 25 leprosy patients autopsied in Hong Kong in World War II with severe malnutrition. Two of these with lepromatous leprosy had low levels of serum proteins and low body weights and signs of kwashiorkor. Moreover, these two patients at autopsy had more widespread leprosy than was observed in the other 23 autopsies and they also had severe ulceration of the skin, indicative of Lazarine leprosy (3). The 
other most quoted reference in support of increased susceptibility to leprosy associated with malnutrition is based on the starvation situation (less than 700 calories/day) facing the 2,500 patients in the Sungei Buloh Leprosarium, Malaysia, also during the Second World War (1). In spite of the horrific mortality (73\%) during this period, it was not claimed that these deaths resulted specifically from leprosy. However, it was observed, for all practical purposes, that the acute reactional manifestations associated with all types of leprosy disappeared throughout the period of gross starvation. Thus from a rate of 100 cases/month of lepromatous reactions (presumably ENL) before the war the rate fell to 2-3/month during the war and similarly for tuberculoid reactions (presumably reversal reactions) the rate was $20 /$ month and for nerve reactions $30-40 /$ month before the war with no cases of either such reactions during the war!

\section{Conclusions}

I conclude from the published literature that there is no definitive evidence supporting malnutrition as a risk factor in leprosy. This does not disprove such an association but underlines the lack of any relevant assessments on the nutritional status of patients with leprosy. However, the immuno-deficiencies known to be associated with more severe PCM are just those that would be likely to increase both the risk of developing leprosy and the severity of the infection once established. The latter is supported by the limited animal studies with M. lepraemurium infections. Furthermore the almost complete absence of reactional episodes among the leprosy patients in Malaysia during the period of severe starvation could have resulted from the immune deficiencies associated with PCM. Thus the associated reduced CMI could have accounted for the absence of reversal reactions, as could have the associated reduced level of $\mathrm{C}_{3}$ been responsible for the reduced incidence of ENL.

Although the evidence for malnutrition as a risk factor in leprosy is meagre and unsubstantiated, I was surprised to find at the time of writing this section that good evidence even for an association between malnutrition and pulmonary tuberculosis was scanty. The difficulty has been to disassociate the several other factors that so frequently are associated with starvation situations. Therefore, out of interest for this meeting, Table 2 presents the data quoted by tuberculosis authorities as most convincingly illustrating malnutrition as a risk factor. The data shows clearly the significantly higher incidence of tuberculosis among the Russian Prisoners of War compared with that of the British and the French before 1945. While the environmental conditions were the same for all nationalities as was the camp diet (1,300-1,600 calories/day) for the period covered, the British, and French (until 1945) received regularly and weekly Red Cross 
parcels of food adding about 1,500 calories/day to their camp diet, the Russians never received such parcels, and the French none after January, 1945 (9).

TABLE 2

Prevalence of Tuberculosis among Prisoners of War in Germany

\begin{tabular}{cccc}
\hline & $\begin{array}{c}\text { French } \\
(1,200)\end{array}$ & $\begin{array}{c}\text { Russian } \\
(1,200-1,000)\end{array}$ & $\begin{array}{r}\text { British } \\
(250)\end{array}$ \\
\hline 1943, July - Dec. & 0 & 6 & 0 \\
1944, Jan. - June & 1 & 14 & 0 \\
" July - Dec. & 1 & 31 & 0 \\
1945, Jan. - April (3 months) & 4 & 11 & 0 \\
\hline
\end{tabular}

The Role of Non-Specific CMI as a Risk Factor in Leprosy

Since the first evidence of the immune mechanisms involved in controlling M. leprae infections was established using experimental animal models and particularly the mouse footpad infection (10), this section will be confined to $M$. leprae infections in animals. Multiplication of $M$. leprae in the footpads of normal mice was limited to a local yield of approximately $10^{6}$ bacilli and then only with inocular some two logs or more less than $10^{6}$. An example of this limited infection is illustrated in Figure 1.

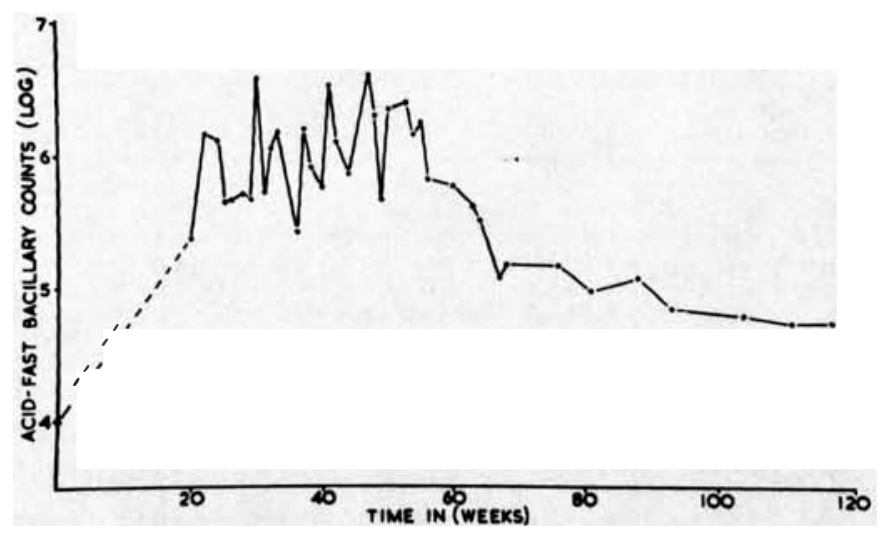

Figure 1. Growth curve of M. leprae in the ears and footpads of normal mice following local inoculation 
It was hypothesised that these features of limited multiplication and dose dependence were controlled by the capacity of the mouse to mount an immune-controlling mechanism when challenged with approximately $10^{6} \mathrm{M}$. leprae. With the knowledge then that tuberculosis infections and other intracellular infections were controlled by CMI rather than humoral immunity, we set out to establish that the same immune mechanism applied to $M_{\text {. leprae. }}$ This was established by demonstrating that when the CMI capacity of mice was obliterated (by thymectomy ( $\mathrm{T}$ ) followed by $900 \mathrm{R}$ total body irradiation), these T-cell deficient mice were capable of supporting unlimited multiplication of $M$. leprae in their footpads, with inocular far in excess of $10^{4}$ bacilli (Figure 2) and the infection spread systemically from the footpads (11).

Figure 2. Growth curves of $M$. leprae in foot pads of normal and thymectomised irradiated mice (T/900r)

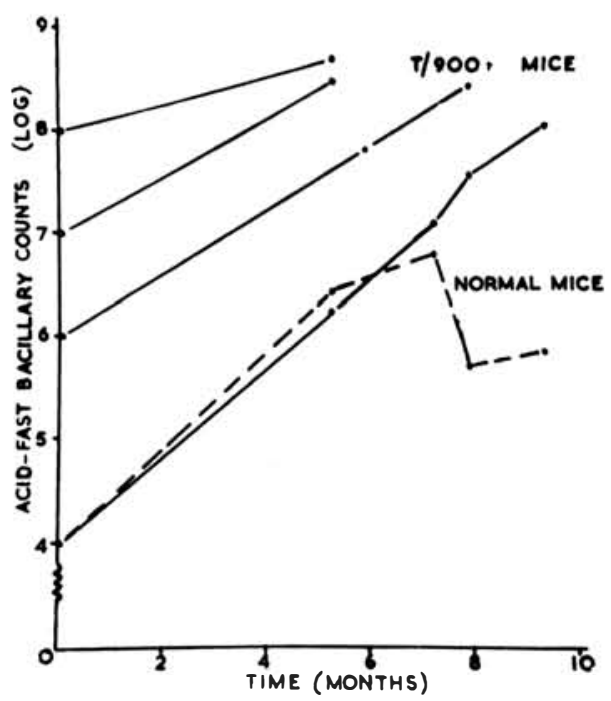

Furthermore, it was demonstrated that the unrestricted and systemic infection resulting in $\mathrm{T} / 900 \mathrm{R}$ mice could be halted by the transfusion of lymphocytes from uninfected syngenic mice (12). While these experimental studies established for the first time the role of CMI in $M$. leprae infections and its importance in explaining a part of the spectrum of leprosy as seen in man, including the importance of CMI in reversal reactions (12), it is important to appreciate that the initial determining CMI mechanisms in these experimental models were non-specific. Similar non-specific depletion of CMI has been established by demonstrating that neonatally thymectomised rats (13) and thymec deficient $\mathrm{Nu}-\mathrm{Nu}$ strains of mice (14) also support unrestricted and systemic 
multiplication of M. leprae.

Finally, in $1 9 7 \longdiv { ( 1 5 ) \text { , it } }$ was demonstrated that the ninebanded armadillo was naturally susceptible to experimental M. leprae infection and that $50 \%$ of such animals supported unlimited multiplication of M. lepraewith diffuse systemic spread.

\section{Conclusion}

While these T-deficient animal models were important in suggesting the important role of CMI in human leprosy, infections, they also indicate that CMI deficiency, non-specifically derived, would be likely to increase the risk factor of infection in man, as well as immunologically determining the outcome of the infection once established in man. Since we do not know why a proportion of ninebanded armadillos is highly susceptible to infections with M. leprae the question of native-susceptibility must be re-considered.

\section{$\underline{\text { Pregnancy and Lactation as Risk Factors in Leprosy }}$}

It has been appreciated for mary years that leprosy may worsen or present for the first time during pregnancy and in the puerperium (4), this applies also to tuberculosis (16). The timings of the leprosy exacerbations during pregnancy are of particular interest and have been most precisely defined from a recent study in Ethiopia $(17,18)$. Thus the critical period for exacerbations in both tuberculoid and lepromatous leprosy is during the third trimestre and the first three months of lactation (Table 3) whereas the incidence of reversal reactions peaked during the first trimestre and again during lactation.

TABLE 3

Worsening of Leprosy During Pregnancy and Lactation

Type of No. of No. of leprosy women pregnancies

No. of patients deteriorating

Pregnancy
(trimestre)
1st 2nd 3rd

Lactation (month)

\begin{tabular}{|c|c|c|c|c|c|c|c|c|c|}
\hline \multirow[t]{2}{*}{ BL } & 40 & 41 & 3 & 3 & 7 & & 3 & 1 & 0 \\
\hline & & & & & Total & 17 & (5) & & \\
\hline \multirow[t]{2}{*}{ LL } & 32 & 35 & 2 & 4 & 13 & & 1 & 0 & 1 \\
\hline & & & & & Tota 1 & 21 & (9) & & \\
\hline
\end{tabular}


These time sequences of the leprosy status in pregnancy coincide with the waning of CMI during pregnancy and its gradual recovery after delivery. The pregnancy-associated waning of CMI, added to all the higher levels of corticosteroids, particularly in the third trimestre, could still further be exacerbated by malnutrition.

\section{Conclusion}

Leprosy is undoubtedly a serious risk factor in pregnancy, necessitating optimum chemotherapy for women with active leprosy and prophylactic therapy for those with "cured", leprosy, and for all to be fed a high protein diet throughout pregnancy and lactation.

\section{Climatic Factors in Leprosy.}

Though there is ever increasing evidence that leprosy is an airborne infection and therefore the portal of entry may be via the lung following the inhalation of $\mathrm{M}$. leprae-infected nuclei (19), as in tuberculosis, much of the evidence for this route of transmission stemmed from intensive studies on nasal discharges from patients with active lepromatous leprosy. From one of the studies it was shown that $M$. leprae remained viable in dried nasal secretions for periods up to 10 days $(20,21)$, but that survival was optimal at high humidities (Table 4). Therefore if the lung is not the only portal of entry the risk of indirect transmission would be greatest in areas with high humidities.

\section{TABLE 4}

Survival of M. leprae in Dried Nasal Secretions Related to Environmental Temperature $\left(\mathrm{T}^{\circ} \mathrm{C}\right)$ and Humidity $(\mathrm{H} \%)$

\begin{tabular}{ccc}
\hline $\begin{array}{c}\text { Time dried } \\
\text { (days) }\end{array}$ & \multicolumn{3}{c}{ Survival } \\
& $\mathrm{T} 36.7^{\circ} \mathrm{C} / \mathrm{H} 77.6 \%$ & $\mathrm{~T} 20.6{ }^{\circ} \mathrm{C} / \mathrm{H} 43.7 \%$ \\
\hline 0 & $6 / 8 *$ & $100 * *$ \\
1 & - & 100 \\
3 & $3 / 8$ & 10 \\
6 & $4 / 8$ & 0 \\
7 & $6 / 8$ & $2 / 12 *$ \\
9 & - & - \\
10 & $2 / 4$ & 0 \\
\hline
\end{tabular}

* Proportion of positive footpads. ** Percent survival. 
$\underline{\text { References }}$

1 Ryrie GA. Some impressions of Sungei Buloh Leper hospital under Japanese occupation, Lepr. Rev, 1948, 18, 10-17.

2 Skinsnes OK. The immunological spectrum of leprosy. In Leprosy in Theory and Practice. Cochrane RG and Davey TF. Eds. Bristol: John Wright and Sons Ltd. 1964; 2nd ed. 156.

3 Skinsnes $\mathrm{OK}$ and Higa $\mathrm{H}$. The role of protein malnutrition in the pathogenesis of ulcerative "Lazarine" leprosy. Int.J. Lepr. $1976,44,346-358$.

4 Davey TF and Schenck RR. The endocrines in leprosy. In Leprosy in Theory and Practice. Cochrane RG and Davey TF Eds. John Wright \& Sons Ltd: Bristol. 1964, 2nd ed., 195.

5 Leiker DL. Some aspects of the epidemiology of leprosy. Int. J. Lepr. 1971, 39, 610-615.

6 Sinha DP and Bang FB. Protein and calorie malnutrition, cellmediated immunity, and BCG vaccination in children from rural West Benga1. Lancet 1976, ii, 531-534.

7 Harland PSE. Tuberculin reactions in malnourished children. Lancet, 1965, ii, 719-721.

8 Yang $\mathrm{HY}$ and Skinsnes OK. Intracellular modulation in cellular immunity. 2. Macrophage enzymes in immunized, proteindepeted and control mice during M. lepraemurium infection. Int. J. Lepr. $1969,17,253$.

9 Cochrane AL. Tuberculosis among prisoners of war in Germany. Brit. Med. J. 1945, ii, 656-658.

10 Shepard CC. The experimental disease that follows the injection of human leprosy bacilli into foot-pads of mice. J. Exp. Med. 1960, Vol. 112, No. 3, 445-454.

11 Rees RJW. Enhanced susceptibility of thymectomized and irradiated mice to infection with Mycobacterium leprae. Nature, 211 , No. 5049, 657, August 6, 1966 .

12 Rees RJW. The impact of experimental human leprosy in the mouse on leprosy research. Int. J. Lepr. 39, 1971, 201-215.

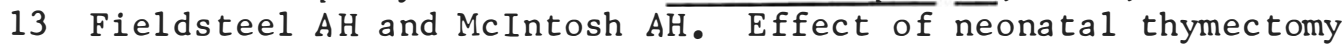
and antithymocytic serum on susceptibility of rats to Mycobacterium leprae infection. Proc. Soc. Exp. Biol. and Med. 1971,138, No. 2, 408-413.

14 Kohsahk Ka Yoneda K, Makino M, Mori T and Ito T. Experimental leprosy with nude mice. Nippon Ri Gakka Zasshi, 1979, 48, No. $1,37-41$.

15 Kirchheimer WF and Storrs EE. Attempts to establish the armadillo (Dasypus novemcinctus, Linn) as a model for the study of leprosy. Int. J. Lepr 1971, 39, 693-702.

16 In The Pathogenesis of tuberculosis. Rich AR Ed. Blackwe11 Scientific Publications, Oxford, 1950. 
17 Duncan ME, Melsom R, Pearson JMH and Ridley DS. The association of pregnancy and leprosy: I. New cases, relapse of cured patients and deterioration in patients on treatment during pregnancy and lactation - results of a prospective study of 154 pregnancies in 147 Ethiopian women. Lepr. Rev. In Press. 1981.

18 Duncan ME, Pearson JMH, Ridley DS, Melsom R and Bjune G. Pregnancy and leprosy: the consequences of alterations of cell mediated and humoral immunity during pregnancy and lactation. Am. J. Obstet.Gynecol. Submitted for publication.

19 Rees RJW and McDougall AC. Airborne infection with Mycobacterium leprae in mice. J. Med. Microbiol. 1977, 10, 63-68.

20 Davey $\mathrm{TF}$ and Rees RJW. The nasal discharge in leprosy; clinical and bacteriological aspects. Lepr. Rev • 1974, 45, $121-134$.

21 Desikan KV. Viability of Mycobacterium leprae outside the human body: Lepr. Rev. 1977, 48, 231-235. 